\title{
ELASTIC PROPERTIES OF THREE VARIETIES OF DATE FRUITS DURING THREE DIFFERENT RIPENING STAGES
}

\author{
M. M. Ibrahim* and A. M. Hassan*
}

\begin{abstract}
The aim of this research work was to determine the physical and elastic properties of date fruits (Phoenix dactylifera) $c v$ (Talees, Khudari and Taghit) during three ripening stages (Khalaal, Rutab and Tamr) to develop a technique that can predict the packing height to protect fruits from mechanical damage. The physical properties include date mass, volume, dimensions, moisture content, bulk density, flesh thickness, and kernel mass. The elastic properties of date fruit include Young's modulus of elasticity $(E)$, firmness coefficient $(F C)$, bioyield stress $(\sigma b)$, bioyield strain $(\varepsilon b)$, rupture stress ( $\sigma r)$, rupture strain $(\varepsilon r)$ and rupture energy (RE). For different varieties, the results showed that ripening stages have a significant effect on physical and elasticity properties. The values of $E$, $F C, \sigma b, \sigma r$ and RE were decreased from Khalaal to Rutab stage, while they increased from Rutab to Tamr stage. Accordingly, the maximum heights of packing box were 141, 106, and $121 \mathrm{~mm}$ for Talees, Khudari and Taghit respectively.
\end{abstract}

Keywords: Date palm, ripening, elasticity, modulus, bioyield, rupture, and stress.

\section{INTRODUCTION}

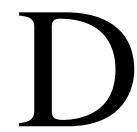

ate palm (phoenix dactylifera, L.) is one of the most important horticultural crops rich in vitamins. Date production in the world is only confined to a small number of countries, most of them being the Arab countries. Date palm is the economic crop in Libya, where production was approximately 150 thousand tons (Arab Agricultural Statistics Yearbook, 2009).

In Libya date palms are distributed mainly in three areas: coastal, middle and southern districts. There are about (6) million date palm trees in Libya grown of about (400) cultivars.

Date fruits pass through several maturity stages, traditionally described by changes in color, texture and taste.

* Assist. Prof., Ag. Eng. Dept., Fac. of Agric., Cairo University. 
Several investigations have shown some of the chemical compositional changes that take place during maturation, including free sugars and tannins (Myhara et al., 1999; Sawaya et al., 1983; Sawaya et al., 1982). Green dates stage (kimri الجمري) are firm in texture with highest moisture and tannin contents. At the Khalaal (خلال) stage, dates begin to lose moisture and form considerable quantities of sucrose. In the Rutab (رطب) stage, the loss of moisture is accelerated, and the fruits become softer in texture, and sucrose is converted into sugars. Dates at Rutab stage are the most desirable since they are at their softest and sweetest states. In the final maturity stage (Tamr - تمر) the fruits contain the least amount of moisture and maintain a soft texture with a sweet taste. Ismail et al., (2001) studied the consumer preference for quality attributes of date (maturity of Tamr stage). Consumer gave weight on the acceptance as: high (color, appearance, and sweetness), medium (fruit size, flesh thickness, chewiness, and solubility).

Knowledge of the physical properties of date fruit is necessary for the design of post harvesting equipment such as cleaning, sorting, grading, kernel removing, and packing. The importance of dimensions is in determining the aperture size of machines, particularly in separation of materials as discussed by Mohsenin (1986). These dimensions can be used in designing machine components and parameters.

Grading fruit, based on weight, reduces packing and handling costs and also provides suitable packing patterns (Khoshnam et al., 2007).

Many studies have been reported on the physical and mechanical properties of fruits, such as bergamot (Rafiee et al. , 2007), coconut (Terdwongworakul et al., 2009), date fruit (Jahorni et al., 2008), kiwi fruit (Lorestani and Tabatabaeefar, 2006), melon (Emadi et al., 2009), orange (Khojastehnazhand et al., 2009) and citrus fruits (Omid et al., 2010). Akar and Aydin (2005) evaluated some physical properties of gumbo fruit varieties as functions of moisture content. Kashaninejad et al. (2006) and Awady and Sayed (1994) determined some physical and aerodynamic properties of peanuts pistachio nuts and kernels as functions of moisture content in order to design processing equipment and 
facilities. Ghonimy and Kassem. (2011) reported that there are significant differences between different production zones of date fruits for each of fruit mass, flesh mass, fruit volume, fruit moisture content, fruit dimensions, flesh thickness, fruit projected area and elasticity of fruits.

Fecete (1994) found that the coefficient of elasticity for tomato and apple can be used to characterize the fruit firmness. Cenkowski et al. (1995) studied the effect of moisture sorption hysteresis on the mechanical behaviour of canola and showed that the modulus of elasticity of the product brought into equilibrium through adsorption was higher than that of the one obtained through desorption at the same moisture content. The other products whose mechanical properties have been studied include kiwi fruit (Abbott and Massie, 1995), apples (Abbott and Lu, 1996) and sea buckthorn berries (Khazaei and Mann, 2004). Anazodo and Chikwendu (1983) developed equations for the calculation of the Poisson's ratio and elastic modulus of circular bodies subjected to radial compression and Dinrifo and Faborode (1993) applied the Hertz's theory of contact stresses to cocoa pod deformation. Anazodo and Norris (1981) noted that the modulus of elasticity, crushing strength and modulus of toughness of corncob all decreased with moisture content.

The aim of this research was to investigate some physical and elastic properties for three varieties of date fruits (Talees, Khudari and Taghit) during three stages of ripening (Khalaal, Rutab and Tamr) to develop a technique that can predict the packing height to protect fruits from mechanical damage.

\section{MATERIAL AND METHODS}

\section{Sample preparation}

This study was carried out at the Faculty of Agriculture, Omar ElMukhtar University, Libya, during season 2010. Physical and mechanical properties of date fruits (Phoenix dactylifera) were determined at three ripening stages. Three varieties (Talees, Khudari, and Taghit) were selected randomly from Sabha (سبها) (located in the western south of Libya). For each variety, 100 date fruits were randomly selected at each ripening stage. The dates were collected from different farms. Dates were 
sorted to discard the damaged fruits, and immediately kept for less than 24 hours in a cold storage at $5{ }^{\circ} \mathrm{C}$.

\section{Physical properties of date fruit}

\subsection{Date fruits dimensions (length and diameter)}

All dimensions of date fruit and kernels were measured by Vernier calliper to an accuracy of $0.1 \mathrm{~mm}$.

\subsection{Date fruit moisture content}

The moisture content was determined for the flesh of dates using AOAC procedures $(\boldsymbol{A O A C}, 1995)$ where the samples were dried at $70^{\circ} \mathrm{C}$ for 48 hours.

\subsection{Mass and bulk density}

The mass of date fruit was determined using a digital balance with an accuracy of $0.01 \mathrm{~g}$. The bulk density of date fruits was calculated using equation (1) by determining the mass of the date and its volume.

$$
D_{b}=\frac{m}{V}
$$

Where;

$$
\begin{aligned}
& D_{b}=\text { The bulk density of date fruit, } \mathrm{g} / \mathrm{cm}^{3} ; \\
& m=\text { Mass of date fruit, } \mathrm{g} ; \\
& V=\text { Volume of date fruit, } \mathrm{cm}^{3} .
\end{aligned}
$$

\section{Mechanical properties of date fruit}

\subsection{Compression test}

The parallel-plate compressive test was carried out to determine the mechanical properties using a universal testing machine (Instron-1000 N) Individual date fruits were uniaxilly compressed at a cross-head speed of $0.5 \mathrm{~mm} / \mathrm{s}$ to a total deformation $10 \mathrm{~mm}$. A plate (diameter $7.5 \mathrm{~cm}$ ) compressed a date flesh slab placed on a mounted fixed table. The contact surfaces were oriented parallel to the compression surfaces during loading (Fig. 1). A random 10 fruits sample of each cultivar at each ripening stage were taken for compression tests. All experiments were carried out at room temperature $\left(23^{\circ} \mathrm{C}\right)$.

The contact area between the parallel-plate disk surface and each tested fruit surface was determined experimentally. The plunger disk surface was covered with a white paper, followed by gently pressing the horizontally oriented upper longitudinal fruit surface in an ink stamp, and 
then allowing the plunger to contact the fruit surface. The resulting contact area traced on the white paper was scanned, and specially developed software that accurately estimates the scanned surface area was used to determine the contact area.
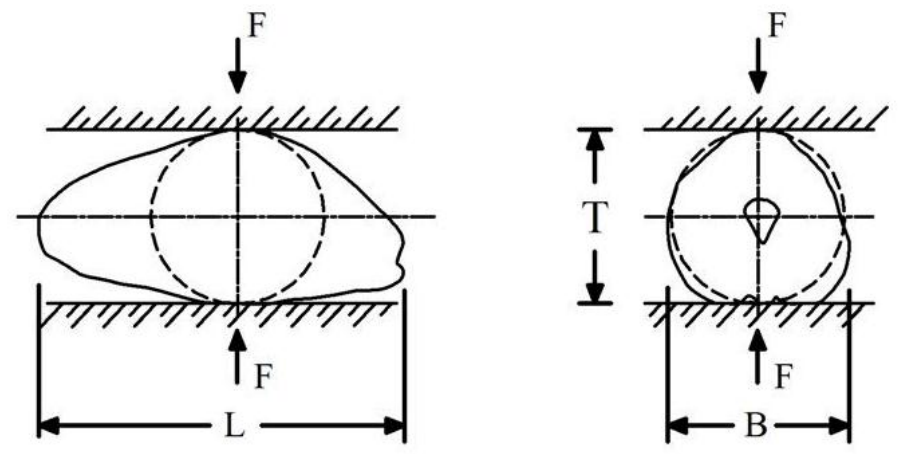

Fig. (1): Date fruit loaded between the two parallel plates

\subsection{Elastic property of date fruit}

A typical force-deformation curve (Mohsenin 1986) is shown in Figure (2). As it is shown, the force-deformation curve exhibited two peak points. The first peak corresponds to the yield point at which kernel damage was initiated. The second peak corresponds to the maximum compressive force.

For stress-strain tests, the following mechanical properties were calculated; the modulus of elasticity (E), firmness coefficient $(F C$ ), bioyield stress $(\sigma b)$, bioyield strain $(\varepsilon b)$, rupture stress $(\sigma r)$, rupture strain $(\varepsilon r)$ and rupture energy toughness $(R E)$.

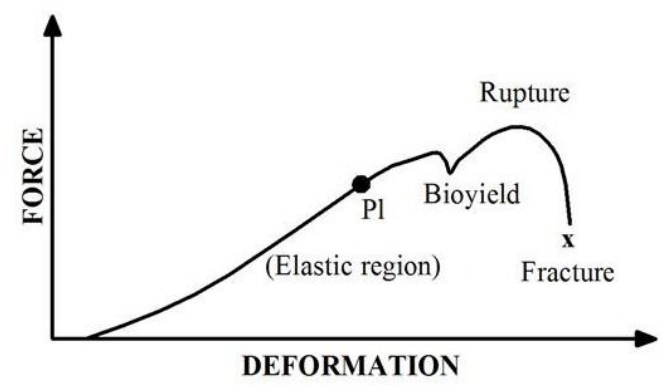

Fig. (2): A typical force-deformation plot for agricultural materials (Mohsenin 1986). 
The Young's modulus of elasticity is a good measure of the elasticity of ideal materials. The behavior of ideal materials is described by the Hooke's law and the model of which is a spring without damper.

The Young's modulus of elasticity $(E)$ for compressive stress is expressed by equation (2).

$$
E=\frac{\sigma}{\varepsilon}
$$

Where;

$$
\begin{aligned}
& E=\text { Young's modulus of elasticity, } \mathrm{kPa} \\
& \sigma=\text { Compressive stress, } \mathrm{kPa} \\
& \varepsilon=\text { Strain, } \mathrm{mm} / \mathrm{mm} .
\end{aligned}
$$

The strain was calculated by dividing the deformation of the fruit by the initial fruit average thickness.

$$
\varepsilon=\frac{\Delta l}{l}
$$

Where;

$$
\begin{aligned}
& \Delta l=\text { Variation in the thickness (deformation), } \mathrm{mm} ; \\
& l=\text { Original thickness, } \mathrm{mm} \text {. }
\end{aligned}
$$

The average stress was calculated by dividing the force on one fruit by the projected area of the fruit as follows:

$$
\sigma=\frac{F}{1000 A_{p}}
$$

Where;

$F=$ force on one fruit, $\mathrm{N}$,

$A_{p}=$ Contact area of date fruit, $\mathrm{mm}^{2}$.

Firmness coefficient $(F C)$ is calculated as the average slope of force deformation curve from zero to point of rupture or failure (Shafiee et al., 2008). $F C$ was calculated by applying the following equation (5) :

$$
F C=\frac{F}{\Delta l}
$$

Toughness $(R E)$ or mechanical energy or work required for rupture was determined by calculating the area under the force - deformation curve from the following equation (Braga et al., 1999):

$$
R E=\frac{F_{r} D_{r}}{2}
$$

Where;

$R E=$ Toughness, $\mathrm{J}$; 
$\mathrm{F}_{\mathrm{r}}=$ the rupture force, $\mathrm{N}$;

$\mathrm{D}_{\mathrm{r}}=$ the deformation at rupture point, $\mathrm{m}$.

The area was measured by using a computer software program (AutoCAD), then, to relate the rupture energy to date fruit volume, it was divided it by date fruit volume.

\subsection{Statistical analysis}

Statistical analysis was carried out using a randomized complete block procedure of the MStat-c statistical package. LSD and Duncan multiple range comparison were used to identify means that were different at probabilities of $5 \%$ or less (Snedecor and Cochran 1976).

\section{Determination of the height of packing box}

The force acting on stacks of fruit may be used to estimate the force acting on a date fruit at the bottom layer of a bulk bin. Figure (3) shows the force $(F)$ acting on date fruit somewhere in stack. In this study, the date fruits are represented by cylinders of an average diameter (d) and a square arrangement which depends on their characteristic diameter and number of fruits.

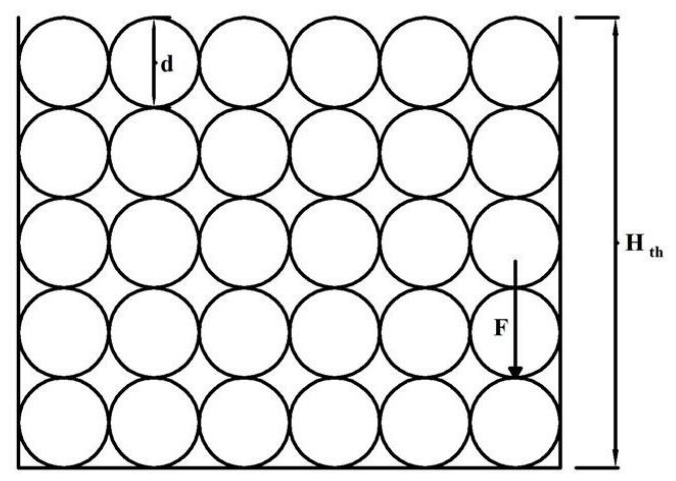

Fig. (3): An elevation view through the stack of date fruits in arrangement.

The following equations ( 7,8 , and 9) calculated the number of fruit of fruits above the bottom layer and consequently the height of the packing box.

$$
\begin{aligned}
& F_{\text {max }}=n \cdot m \\
& H_{t h}=d \cdot(n+1) \\
& H_{a c t}=\frac{H_{t h}}{S . F .}
\end{aligned}
$$

Where: 
$F_{\max }=$ Maximum allowable force on a date fruit at the bottom layer, $\mathrm{N}$.

$H_{t h} \quad=$ Maximum depth of fruit in box, (without mechanical damage), mm.

$H_{a c t} \quad=$ Actual depth of fruit in box, mm.

$n \quad=$ Number of fruits above the last fruit at bottom layer.

$m \quad=$ Fruit weight, $\mathrm{N}$.

$d \quad=$ Fruit diameter, $\mathrm{mm}$.

S. $F . \quad=$ Safety factor $(\approx 1.5)$ as design factor to avoid any unexpected risk.

\subsection{Determination of the contact stress}

Heinrich Hertz (Shigley et al., 2008) proposed a solution for contact stress in two elastic isotropic bodies, such as the case of two cylinders (line contact) of the same material touching each other and attempted to find the magnitude of the maximum pressure. Figure (4) shows two cylinders of length $l$ (the length of cylinder $=$ fruit length) and diameters $\mathrm{d} 1$ and $\mathrm{d} 2$. The area of contact is a narrow rectangle of width $2 \boldsymbol{b}$ and length $\boldsymbol{l}$, and the pressure distribution is elliptical.

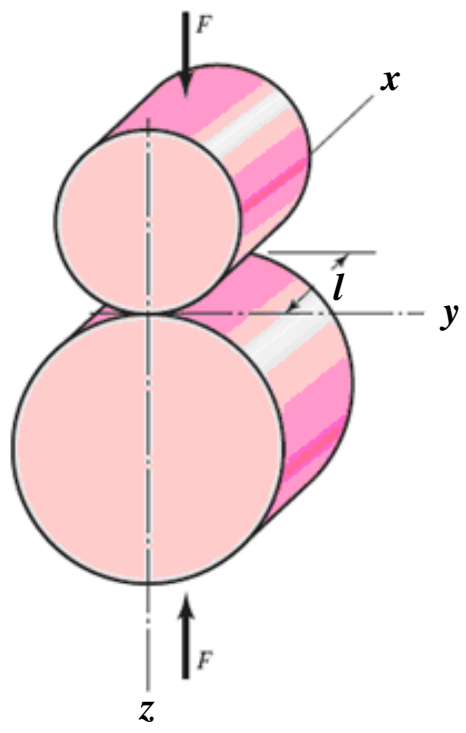

(1)

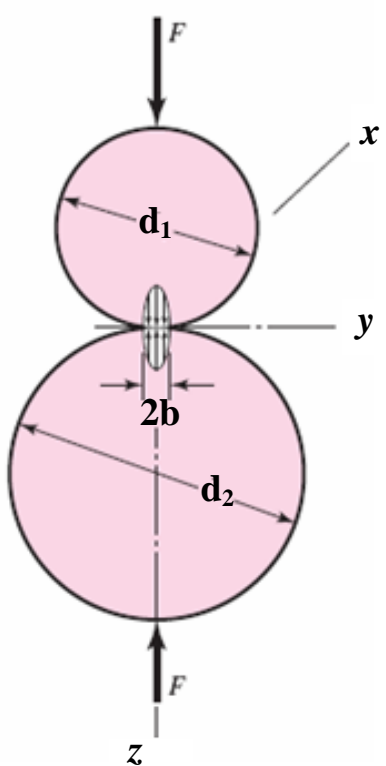

(2)

Fig. (4): Line contact of two cylinders: (1) Two circular cylinders held in contact by forces $F$ uniformly distributed along cylinder length $l$. (2) Contact stress has an elliptical distribution across the contact zone width $2 b$. 
The half-width $\boldsymbol{b}$ is given by the equation (Shigley et al., 2008):

$$
b=\sqrt{\frac{2 F}{\pi l} \frac{\left(1-\mu_{1}^{2}\right) / E_{1}+\left(1-\mu_{2}^{2}\right) / E_{2}}{1 / d_{1}+1 / d_{2}}}
$$

Where:

$\mathrm{b}=$ half of contact width, $\mathrm{mm}$.

$\mathrm{F}=$ Acting force on the two cylinders, $\mathrm{N}$.

$l=$ contact length, $\mathrm{mm}$.

$E_{1}, E_{2}=$ Modulus of elasticity for cylinders (1) and (2), Pa.

$\mu_{1}, \mu_{2}=$ Poisson ratio for cylinders (1) and (2), dimensionless.

$\mathrm{d}_{1}, \mathrm{~d}_{2}=$ Diameter for cylinder (1) and (2), mm.

The maximum pressure $\left(P_{\max }, \mathrm{Pa}\right)$ is called the Hertz (compressive) stress which occurs at the center and is given by following equation:

$$
p_{\max }=\frac{2 F}{\pi b l}
$$

\section{RESULTS AND DISCUSSIONS}

\section{Physical properties of date fruit}

The averages values of date fruit mass, flesh mass, kernel mass, fruit volume, bulk density, moisture content, fruit length, fruit diameter and flesh thickness are shown in table (1).

For Talees variety, moisture contents were measured as 70.87, 60.6 and $21.79 \%$ w.b. for Khalaal, Rutab and Tamr respectively. Results showed that the moisture content decreased by increasing the ripening. The average of dimensions were $27.4 \mathrm{~mm}$ in length, $17.4 \mathrm{~mm}$ in width and $10.11 \mathrm{~mm}$ in thickness for Khalaal stage, $36.5 \mathrm{~mm}$ in length, $19.1 \mathrm{~mm}$ in width and $11.5 \mathrm{~mm}$ in thickness for Rutab stage, and $35.3 \mathrm{~mm}$ in length, $19.4 \mathrm{~mm}$ in width and $11.57 \mathrm{~mm}$ in thickness for Tamr stage. Date dimensions increased from Khalaal stage to Rutab stage, while decreased from Rutab to Tamr. Average fruit mass was 7.5, 11.5 and $10.6 \mathrm{~g}$ for Khalaal, Rutab and Tamr respectively. Results showed that the fruit mass increased from Khalaal stage to Rutab stage, while decreased from Rutab to Tamr. The same trend was found for Khudari and Taghit varieties. With Taghit variety the fruit mass was less than Talees and Khudari. 
Data proved that the physical properties of date fruit were greatly influenced by ripening stage with all varieties.

For the three varieties, the statistical analysis (at 5\% level) showed significant differences for most physical properties of date fruits during three stages of ripening (Khalaal, Rutab and Tamr).

\section{Mechanical properties of date fruit}

The mechanical properties of date fruit varieties at different ripening stages included modulus of elasticity $(E)$, firmness coefficient $(F C)$, bioyield stress $(\sigma b)$, bioyield strain $(\varepsilon b)$, rupture stress $(\sigma r)$, rupture strain $(\varepsilon r)$, and rupture energy $(R E)$ as shown in table (1). Ripening stages for date fruit showed a significant effect on mechanical properties $(\mathrm{P}<0.01)$.

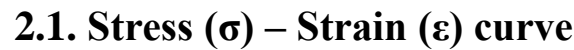

Figure (5: a, b, c) shows the stress-strain curve of date palm (Talees, Khudari and Taghit varieties) during different ripening stages. It is clear that, before the point called proportional limit $\left(\mathrm{P}_{1}\right)$. Generally, the elastic limit is the limit beyond which the date will no longer go back to its original shape when the load is removed, or it is the maximum stress that may be developed such that there is no permanent setting when the load is entirely removed. For the three varieties, the statistical analysis (at 5\% level) showed significant differences for most elasticity properties of date fruits during three stages of ripening (Khalaal, Rutab and Tamr).

The elastic limits were (110.5, 40 and $50 \mathrm{kPa}),(3.3,3.3$, and $4.4 \mathrm{kPa})$, and $(5.1,15$, and $10.4 \mathrm{kPa})$ for Talees, Khudari, and Taghit respectively. The results showed that the elastic limit decreased from Khalaal to Rutab stage, while increased from Rutab to Tamr. The reason may be due to the major changes which take place in the structural tissues during the ongoing maturation process and change from Khalaal to Rutab to Tamr stage of maturity. The most significant changes are in sugar type which converts from sucrose to fructose and glucose as a result of enzymatic action during the maturation process. The changes in pectin by pectinase enzyme lead to softness in the date structure at the Rutab stage compared to the Khalaal stage despite the reduction in moisture content at the Rutab stage. for Talees is greater than Taghit and Khudria at Khalaal and Rutab stages, but Tamr stage, the elastic limit with Kudria is greater than Taghit and Talees. 
Table (1). Physical and mechanical properties of the date fruits.

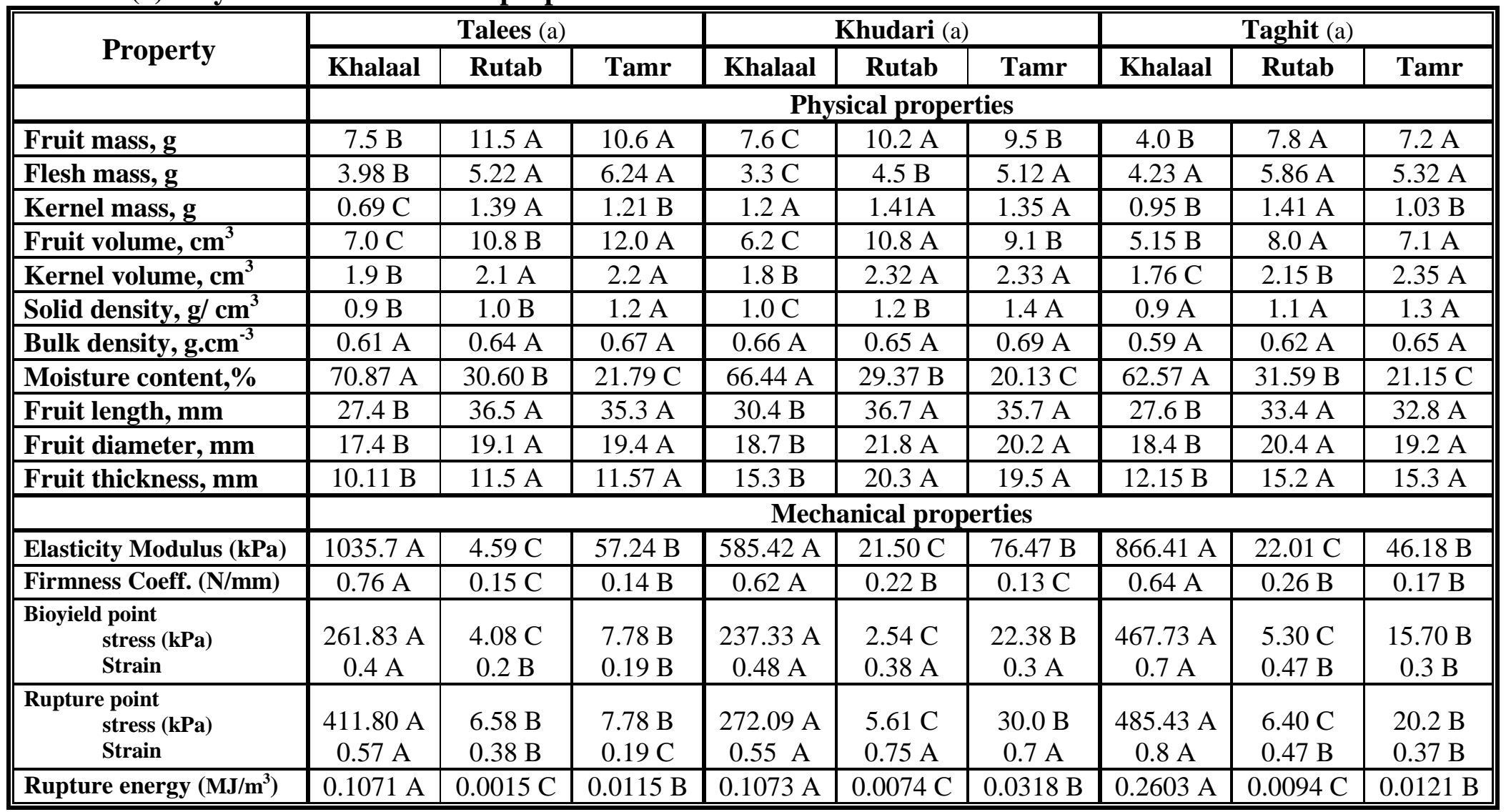

(a) Mean values with different letters are significantly different (<5\% level). 

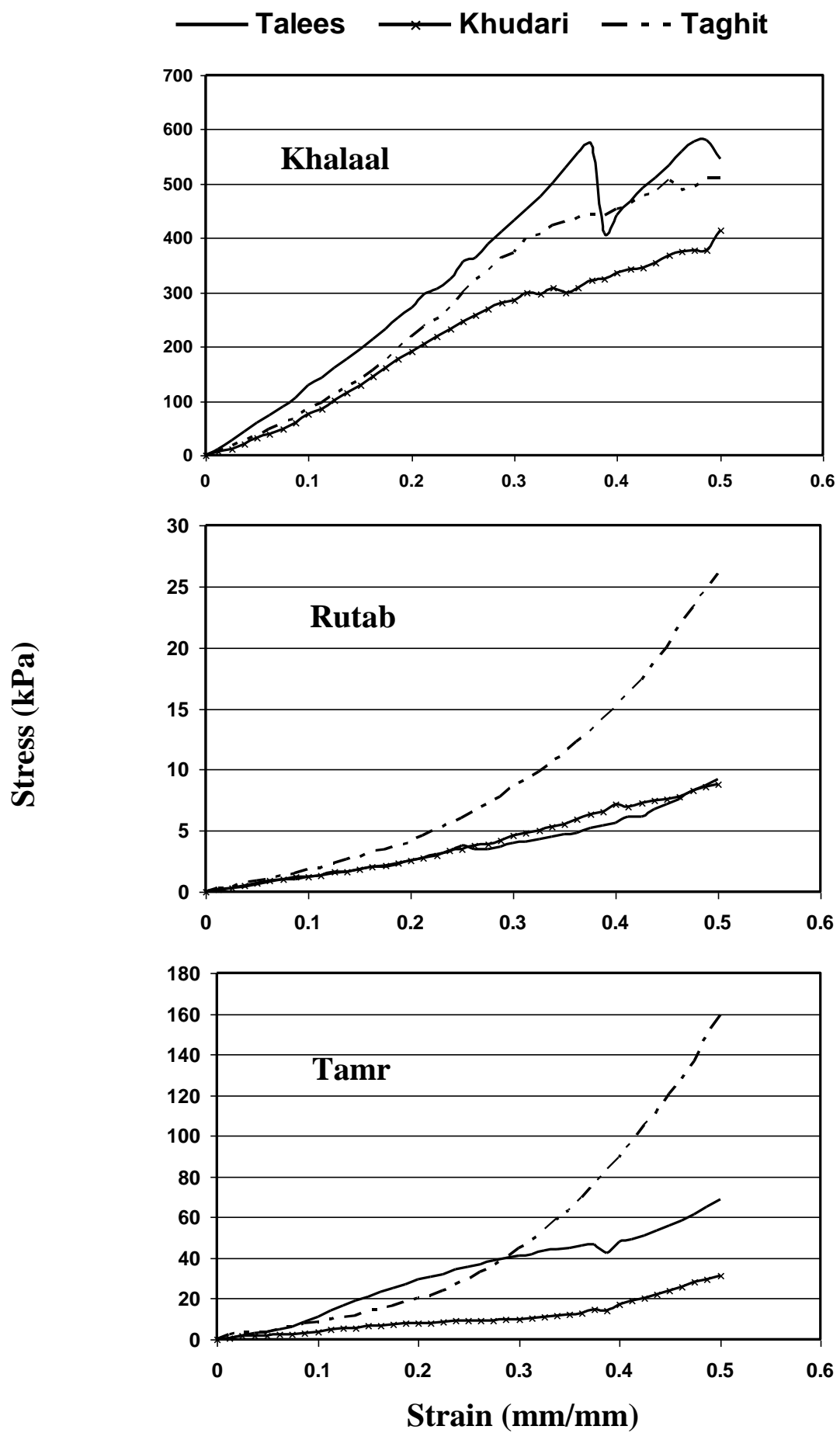

Fig. (5): Stress- strain curves of date fruit varieties at different ripening stages. 


\subsection{Modulus of elasticity $(E)$}

The average values of Young's modulus of elasticity $(E)$ for date fruits at different ripening stages and varieties are shown in table (1) and figure (6-a). It is clear that the modulus of elasticity $(E)$ decreased from Khalaal to Rutab stage, while increased from Rutab to Tamr which was common trend for all varieties.

For Talees variety, the values of modulus of elasticity were $1035.7 \mathrm{kPa}$, $4.59 \mathrm{kPa}$ and $57.27 \mathrm{kPa}$ for Khalaal, Rutab and Tamr stages respectively. For Khudari variety, the values of modulus of elasticity were $585.42 \mathrm{kPa}$, $21.50 \mathrm{kPa}$ and $76.47 \mathrm{kPa}$ for Khalaal, Rutab and Tamr stages respectively. For Taghit variety, the values of $E$ were $866.41 \mathrm{kPa}, 22.01$ $\mathrm{kPa}$ and $46.18 \mathrm{kPa}$ for Khalaal, Rutab and Tamr stages respectively.

In case of Khalaal stage of ripening; $E$ of Talees was greater than Taghit and Khudari, In case of Rutab stage; $E$ of Taghit was greater than Khudari and Talees, but in case of Tamr stage; $E$ of Khudari was greater than Talees and Taghit.

For the three varieties, the statistical analysis (at 5\% level) showed significant differences for $E$ of date fruits during the three stages of ripening (Khalaal, Rutab and Tamr).

\subsection{Firmness Coefficient $(F C)$}

The average values of firmness coefficient $(F C)$ for date fruits at different ripening stages and varieties are shown in table (1) and figure (6-b). It is clear that the firmness coefficient $(F C)$ decreased from Khalaal to Tamr stage, for all different varieties.

For Talees variety, the values of $F C$ were $0.76,0.15$, and $0.14 \mathrm{~N} / \mathrm{mm}$ for Khalaal, Rutab and Tamr stages respectively. For Khudari variety, the values of $F C$ were $0.62,0.23$, and $0.13 \mathrm{~N} / \mathrm{mm}$ for Khalaal, Rutab and Tamr stages respectively. For Taghit variety, the values of $F C$ were 0.64 , 0.26 , and $0.17 \mathrm{~N} / \mathrm{mm}$ for Khalaal, Rutab and Tamr stages respectively.

The results show that the $F C$ of Talees variety is greater than Taghit and Khudari with Khalaal stage of ripening, for Taghit variety; the $F C$ is greater than Khudari and Talees with Rutab stage of ripening, but for Khudari, the $F C$ was greater than Talees and Taghit with Tamr stage of ripening. 
For the three varieties, the statistical analysis (at 5\% level) showed significant differences for $F C$ of date fruits during the three stages of ripening (Khalaal, Rutab and Tamr).

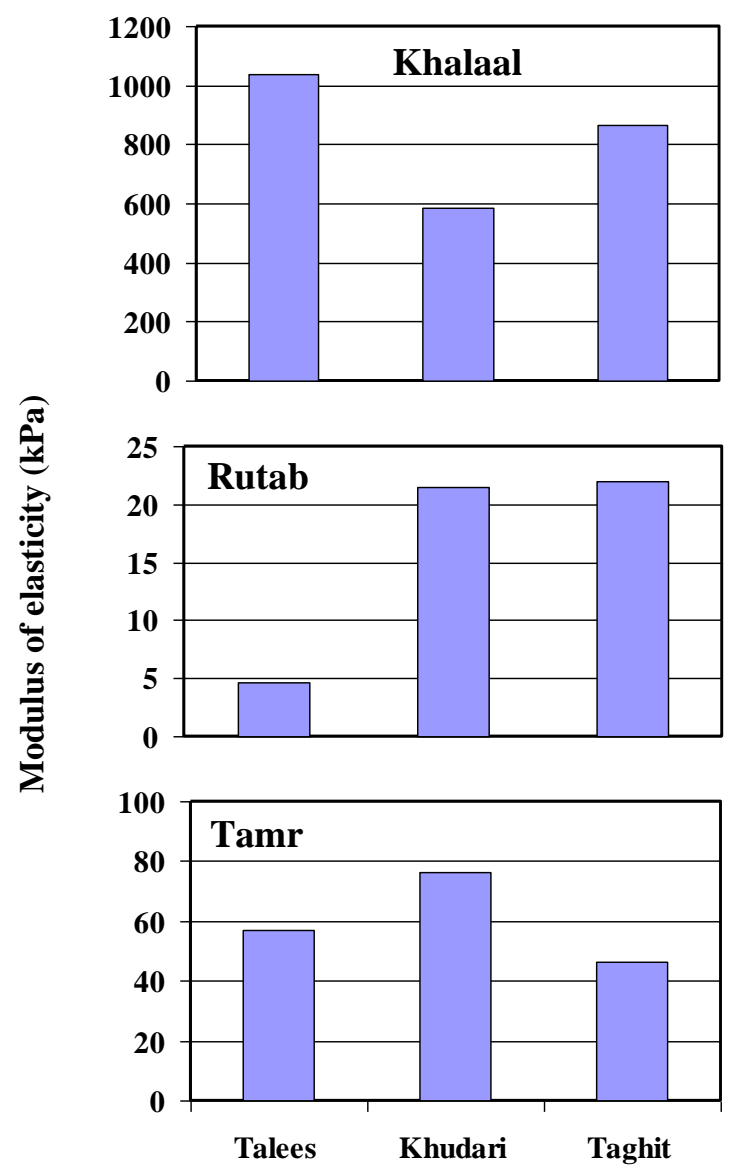

(a)

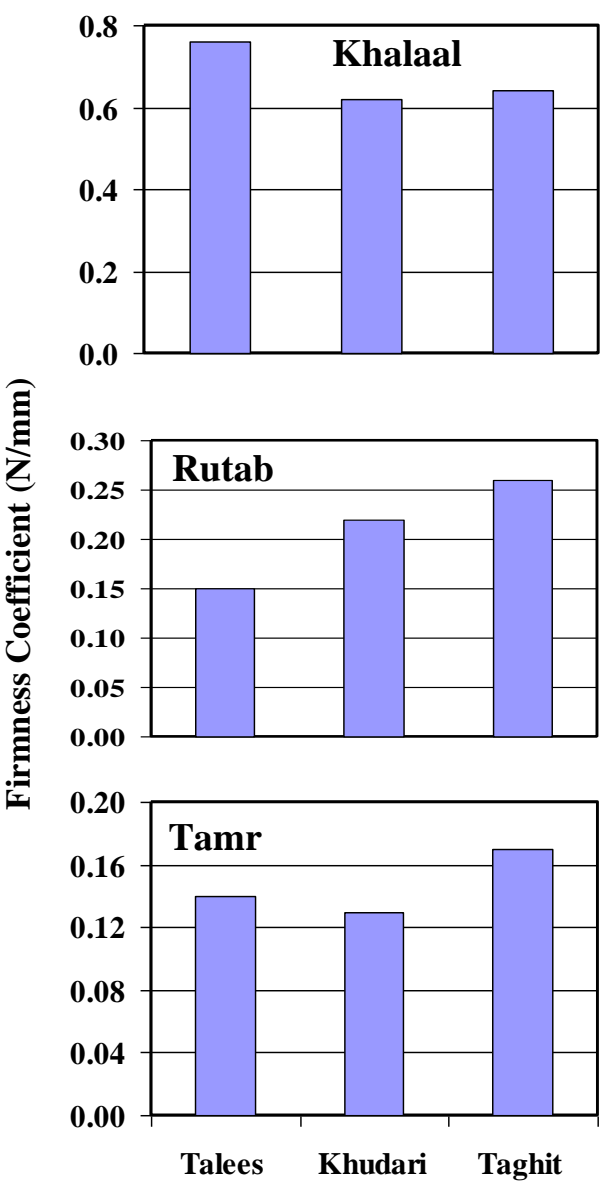

(b)

Fig. (6): Modulus of elasticity $(E)$ and firmness coefficient $(F C)$ for date fruit varieties under study at different ripening stages.

\subsection{Bioyield stress $(\sigma b)$}

The average values of bioyield stress $(\sigma b)$ for date fruits at different ripening stage and varieties are shown in table (1) and figure (7-a). It is clear that the bioyield stress $(\sigma b)$ decreased from Khalaal to Rutab stage, while increased from Rutab to Tamr, with all varieties. In case of Talees variety, the values of $(\sigma b)$ were $261.83,4.08$, and $7.78 \mathrm{kPa}$ for Khalaal, Rutab and Tamr stages respectively. In case of Khudari variety, the 
values of $(\sigma b)$ were $237.33,2.54$, and $22.38 \mathrm{kPa}$ for Khalaal, Rutab and Tamr stage respectively. In the case of Taghit variety, the values of $(\sigma b)$ were $467.75,5.30$, and $15.70 \mathrm{kPa}$ for Khalaal, Rutab and Tamr stages respectively.

For the three varieties, the statistical analysis (at 5\% level) showed significant differences for $\sigma b$ of date fruits during the three stages of ripening (Khalaal, Rutab and Tamr).

\subsection{Bioyield strain $(\varepsilon b)$}

The average values of bioyield strain $(\varepsilon b)$ for date fruits at different ripening stages and varieties are shown in table (1). It is clear that the bioyield strain $(\varepsilon b)$ decreased from Khalaal to Tamr stage, with all different varieties.

In the case of Talees variety, the values of $\varepsilon b$ were $0.4,0.2$, and 0.19 $\mathrm{mm} / \mathrm{mm}$ for Khalaal, Rutab and Tamr stages respectively. In the case of Khudari variety, the values of $\varepsilon b$ were $0.48,0.38$, and $0.3 \mathrm{~mm} / \mathrm{mm}$ for Khalaal, Rutab and Tamr stages respectively. In case of Taghit variety the values of $\varepsilon b$ were $0.7,0.47$, and $0.3 \mathrm{~mm} / \mathrm{mm}$ for Khalaal, Rutab and Tamr stages respectively.

The results show that the $\varepsilon b$ of Taghit variety was greater than Khudari and Talees in all ripening stages.

The results show that the $(\sigma b)$ of Taghit variety was greater than Talees and Khudari with Khalaal and Rutab stages of ripening. However for Khudari, the $(\sigma b)$ was greater than Talees and Taghit with Tamr stage of ripening.

For the three varieties, the statistical analysis (at 5\% level) showed significant differences for $\varepsilon b$ of date fruits during the three stages of ripening (Khalaal, Rutab and Tamr).

\subsection{Rupture stress $(\sigma r)$}

The average values of rupture stress $(\sigma r)$ for date fruits at different ripening stages for the different varieties are shown in table (1) and figure (7-b). It is clear that the rupture stress $(\sigma r)$ decreased from Khalaal to Rutab stage, while increased from Rutab to Tamr, with all different varieties. 
In case of Talees variety, the values of $\sigma r$ were $411.80,6.58$, and 7.78 $\mathrm{kPa}$ for Khalaal, Rutab and Tamr stages respectively. In case of Khudari variety, the values of $\sigma r$ were $272.09,5.61$, and $30 \mathrm{kPa}$ for Khalaal, Rutab and Tamr stages respectively. In case of Taghit variety, the values of $\sigma r$ were 485.43, 7.40, and $20.20 \mathrm{kPa}$ for Khalaal, Rutab and Tamr stages respectively.

The results showed that the $\sigma r$ of Taghit variety was greater than Talees and Khudari with Khalaal and Rutab stages of ripening, but for Khudari, the rupture stress was greater than Talees and Taghit with Tamr stage of ripening.

For the three varieties, the statistical analysis (at 5\% level) showed significant differences for $\sigma r$ of date fruits during the three stages of ripening (Khalaal, Rutab and Tamr).
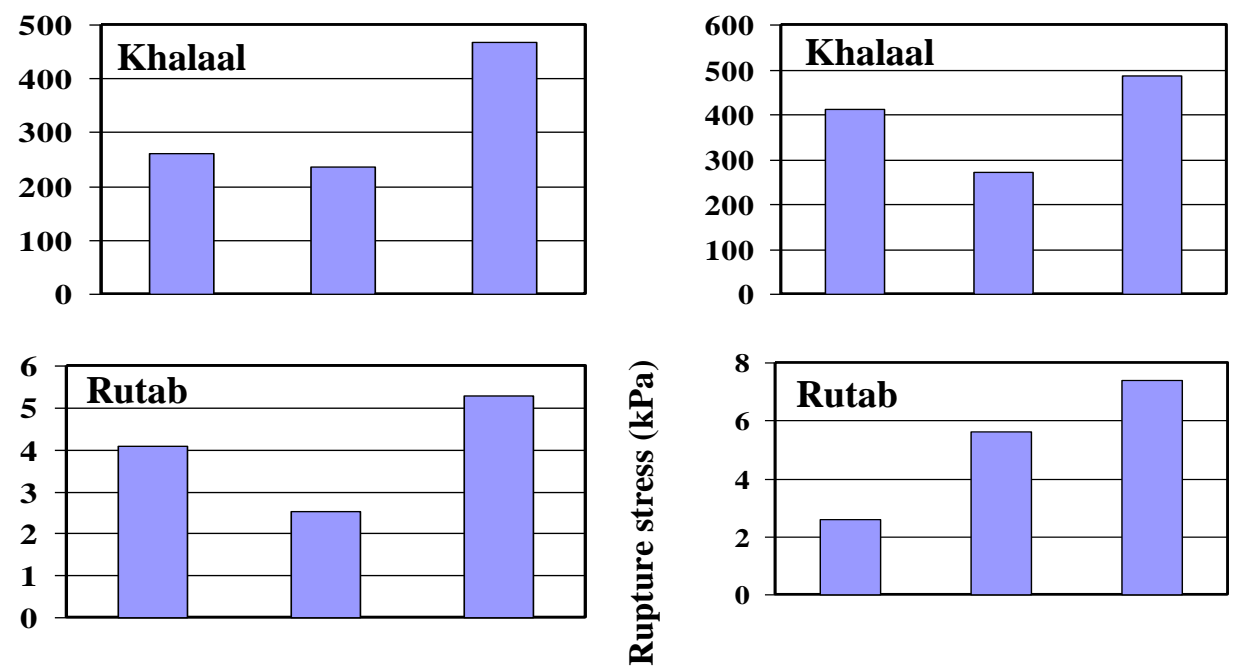

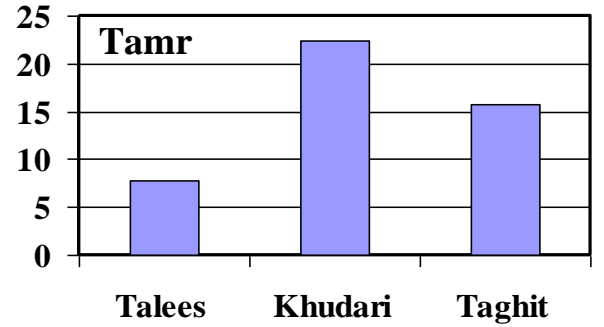

(a)

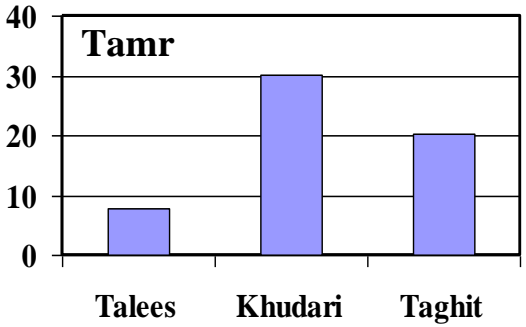

(b)

Fig. (7): Bioyield stress $(\sigma b)$ and rupture stress $(\sigma r)$ for date fruit varieties under study at different ripening stages. 


\subsection{Rupture strain ( $\varepsilon r)$}

From the calculated results of rupture strain for date fruits at different ripening stages with different varieties, as shown in table (1) and figure (8-a), it can be found that the rupture strain decreased from Khalaal to Tamr stages, with Talees and Taghit varieties, but in the case of Khudari variety the rupture strain increased from Khalaal to Rutab stages then decreased in Tamr stage.

In the case of Talees variety, the values of rupture strain were $0.57,0.38$, and $0.19 \mathrm{~mm} / \mathrm{mm}$ for Khalaal, Rutab and Tamr stages respectively. In case of Khudari variety, the values of rupture strain were $0.55,0.75$, and $0.7 \mathrm{~mm} / \mathrm{mm}$ for Khalaal, Rutab and Tamr stages respectively. In the case of Taghit variety, the values of rupture strain were $0.8,0.47$, and 0.37 $\mathrm{mm} / \mathrm{mm}$ for Khalaal, Rutab and Tamr stages respectively.

The results showed that the rupture strain of Taghit variety was greater than Talees and Khudari with Khalaal stage of ripening, but for Khudari, the rupture strain was greater than Talees and Taghit with Rutab and Tamr stages of ripening.

For the three varieties, the statistical analysis (at 5\% level) showed significant differences for $\varepsilon r$ of date fruits during the three stages of ripening (Khalaal, Rutab and Tamr).

\subsection{Rupture energy $(R E)$}

The average values of rupture energy $(R E)$ for date fruits at different ripening stages and varieties are shown in table (1) and figure (8-b). It is clear that, the rupture energy $(R E)$ decreased from Khalaal to Rutab stage, while increased from Rutab to Tamr, with all different varieties.

In case of Talees variety, the values of $R E$ were $0.1071,0.0015$, and $0.0115 \mathrm{MJ} / \mathrm{m}^{3}$ for Khalaal, Rutab and Tamr stages respectively. In the case of Khudari variety, the values of $R E$ were $0.1073,0.0074$, and $0.0318 \mathrm{MJ} / \mathrm{m}^{3}$ for Khalaal, Rutab and Tamr stages respectively, where for Taghit variety, the values of $R E$ were $0.2603,0.0094$, and 0.0121 $\mathrm{MJ} / \mathrm{m}^{3}$ for Khalaal, Rutab and Tamr stages respectively.

The results show that the $R E$ of Taghit variety was greater than Talees and Khudari with Khalaal stage of ripening, but for Khudari, the rupture 
energy was greater than Talees and Taghit with Rutab and Tamr stages of ripening.

For the three varieties, the statistical analysis (at 5\% level) showed significant differences for $R E$ of date fruits during the three stages of ripening (Khalaal, Rutab and Tamr).

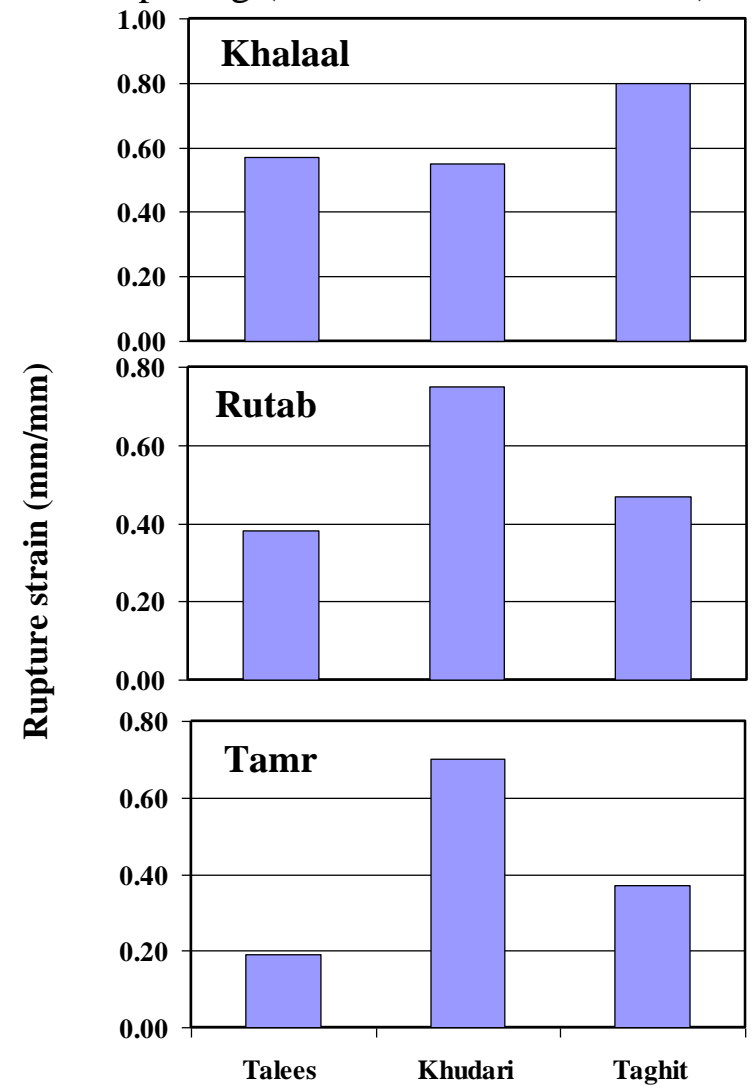

(a)

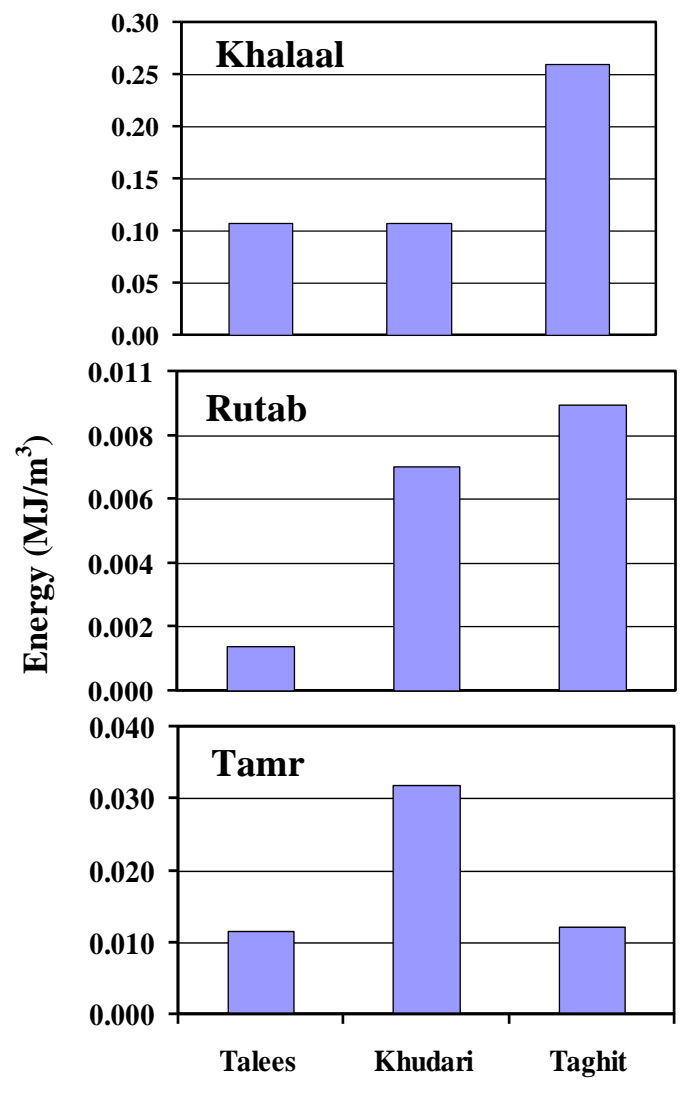

(b)

Fig. (8): Rupture strain ( $\varepsilon r)$ and energy $(R E)$ for date fruit varieties under study at different ripening stages.

In general, the mechanical properties of date fruit are influenced by varieties and ripening stage. As concluded from the results of the present study, each of E, FC, ob, or and RE decreased from Khalaal to Rutab stage then increased at Tamr stage. The physical and mechanical properties of the three date fruit varieties namely, Talees, Khudari and Taghit are important in designing machine used for harvesting and post harvest handling of dates during ripening stages. 
PROCESS ENGINEERING

\section{Predicting the height of packing box}

In order to get optimum (prediction) of the height of packing box the following procedure was applied.

Applying equations (10) and (11) considering the following assumption:

$d_{1}=d_{2}=$ fruit thickness.

$E_{1}=E_{2}=$ Modulus of elasticity for date fruit.

$\mu_{1}=\mu_{2}=$ Poisson ratio of date fruit (the absolute value of the transverse strain to the corresponding axial strain resulting from uniformly distributed axial stress below the proportional limit of the material, it was measured $\approx 0.4$.

$l \quad=$ Fruit length.

$P_{\max }=$ Bioyield stress of date fruit.

Substitute equation (10) in equation (11) use try and error method to calculate the maximum allowable force $\left(F_{\max }\right)$ for the three varieties in Rutab stage (the bioyield stress in Rutab stage is less than other stages), the values of $n, H_{t h}$, and $H_{a c t}$ can be calculated as shown in table (2).

Table (2): The calculation results of $F_{\max }, H_{t h}$, and $H_{a c t}$.

\begin{tabular}{|l|c|c|c|}
\hline & Talees & Khudari & Taghit \\
\hline$F_{\max }, N$ & 2.00 & 0.70 & 0.855 \\
\hline$N$ & 17.391 & 6.8627 & 10.962 \\
\hline$H_{t h}, \mathrm{~mm}$ & 211.50 & 159.61 & 181.82 \\
\hline$H_{a c t}, \mathrm{~mm}$ & 141 & 106.41 & 121.21 \\
\hline
\end{tabular}

Therefore, the maximum heightsof packing box which does not result in mechanical damage were141, 106, and $121 \mathrm{~mm}$ for Talees, Khudari and Taghit respectively.

\section{CONCLUSION}

The obtained results of physical and mechanical properties of the three date fruit varieties during three stages of ripening can be summarized as follows:

1. There were significant differences between ripening stages of date fruits for most physical properties. 
2. There were significant differences between ripening stages of date fruits for mechanical properties.

3. For different varieties, the values of E, FC, $\sigma b$, or and RE decreased from Khalaal to Rutab stage then increased from Rutab to Tamr stages.

4. The different measured mechanical properties followed the same trend which reflected their state behaviour at the three stages same of ripening for the three tested varieties: decreasing through Khalaal to Rutab stages then increasing through Rutab to Tamr stages.

5. The maximum heights of packing box are 141, 106, and $121 \mathrm{~mm}$ for Talees, Khudari and Taghit respectively.

\section{REFERENCES}

Abbott, J. A. and D. R. Massie. 1995. Non-destructive dynamic force/deformation measurement of kiwifruit firmness (Actinidia Delicious). Trans. ASAE, 38(6): 1809 - 1812.

Abbott, J. A. and R. Lu. 1996. Anistropic mechanical properties of apples. Trans. ASAE, 39(4): $1451-1459$.

Akar R. and C. Aydin. 2005. Some physical properties of gumbo fruit varieties. J. Food Eng., 66: 387-393.

Anazodo, U. G. N. and E. R. Norris. 1981. Effects of genetic and cultural practices on the mechanical properties of corncobs. J. Agr. Eng. Res., 26: 97 - 107.

Anazodo, U. G. N. and S. C. Chikwendu. 1983. Poisson's ratio and elastic modulus of radially compressive biomaterials - I: small deformation approximation. Transactions of the ASAE, 26(3): $923-$ 929.

AOAC. 1995. Official methods of analysis (16 ${ }^{\text {th }}$ ed.). Association of Official Analytical Chemists. Wash., DC.

Arab Agricultural Statistics Yearbook. 2009. Plant production. Part 3. Vol. 29.

Awady, M. N. and A. S. El Sayed. 1994. Separation of peanut seeds by air stream. M J A E, 11 (1): 137-147. 
PROCESS ENGINEERING

Braga, G. C., Couto, S. M., Hara, T., and Neto, J. T. P. A. 1999. Mechanical behaviour of macadamia nut under compression loading. J. Ag. Eng. Res., 72: 239-245.

Cenkowski, S., Q. Zhang and W.J. Crerar. 1995. Effect of sorption hysteresis on the mechanical behaviour of canola. Transactions of the ASAE, 38(5): $1455-1460$.

Dinrifo, R. R. and M. A. Faborode. 1993. Application of Hertz's theory of contact stresses to cocoa pod deformation. J. Ag. Eng. and Tec., 1: $63-73$.

Emadi B., M. H. Abbaspour-Fard, and P. Yarlagadda. 2009. Mechanical properties of melon measured by compression, shear, and cutting modes. I. J. Food Properties; 12(4): 780-790.

Fecete, A. 1994. Elasticity characteristics of fruits. International Agrophysics, 8(3): 411- 414.

Ghonimy, M. I., and M. A. Kassem. 2011. The elasticity characteristics of palm date. Misr, J. Ag. Eng., 28 (2): 386 - 400.

Ismail, B., Haffar, I., Baalbaki, R., and J. Henry. 2001. Development of a total quality scoring system based on consumer preference weightings and sensory profiles: application to fruit dates (Tamr). Food Quality Preference, 12: 499-506.

Jahorni, M., S. Rafiee, A. Jafari, BMR. Ghasemi, R. Mirasheh, and S. S. Mohtasebi. 2008. Some physical properties of date fruit (cv. Dairi). I. Agrophys., 22:221-224.

Kashaninejad M., A. Mortazavi, A. Safekordi, and L. G. Tabil. 2006. Some physical properties of pistachio ( Pistacia veraL.) nut and its kernel. J. Food. Eng., 72, 30-38. Agrophysics. 22: 221-224.

Khazaei, J. and D. D. Mann. 2004. Effects of temperature and loading characteristics on mechanical and stress relaxation properties of sea buckthorn berries, Part 1: Compression tests. Ag. Eng. I. Ejournal, Manuscript FP 03 011, http//cigr-ejournal.tamu.edu/html/Volume 6, April. 
PROCESS ENGINEERING

Khojastehnazhand M., M. Omid, and A. Tabatabaeefar. 2009. Determination of orange volume and surface area using image processing technique. I. Agrophys.; 23: 237-24.

Khoshnam, F., A. Tabatabaeefar, M. Ghasemi Varnamkhasti and A. Borghei. 2007. Mass modeling of pomegranate (Punica granatum L.) fruit with some physical characteristics. Scientia Horticulturae 114: 1, 21-26.

Lorestani, A. N., and A. Tabatabaeefar. 2006. Modeling the mass of kiwi fruit by geometrical attributes. I. Agrophys. 20: 135-139.

Mohsenin, N. N. 1986. Physical properties of plant and animal materials, 2nd ed. Gordon and Breach Sc. Publishers

Myhara, R. M., Karkalas, J., and M. S. Taylor. 1999. The composition of maturing Omani dates. Journal of the Science and Food Agriculture, 79, 1-6.

Omid M., M. Khojastehnazhand, and A. Tabatabaeefar. 2010. Estimating volume and mass of citrus fruits by image processing technique. J. Food Eng.; 100(2): 315-321.

Rafiee, S., M. Keramat, A. Jafari, A. R. Keyhani and R. Mirasheh. 2007. Determination of dimension and mass of date (ghasb). Proc. I. Conf. on Innovations in Food and Bioprocess Tech. , Thailand.

Sawaya, W. N., Khalil, J. K., Safi, W. N., and A. Al-Shalhat. 1983. Physical and chemical characterization of three Saudi date cultivars at various stages of development. Canadian Inst. Food Sc. and Tec., $16,87-91$.

Sawaya, W. N., Khatchadourian, H. A., Khalil, J. K., Safi, W. M., and A. Al-Shalhat. 1982. Growth and compositional changes during various developmental stages of some Saudi Arabian date cultivars. J. Food Sc., 47: 489-492.

Shafiee, S. , A. M. Motlagh, A. R. Didar and S. Minaee. 2008. Investigation the effect of skin on mechanical behaviour of apple. J. Food Tec., 6(2): 86 -91.

Shigley, J. E., C. R. Mischke, C. R. and R. G. Budynas. 2008. Mechanical engineering design. MC Graw-Hill, Singapore.

Snedecor, G. A. and W. G. Cochran. 1976. Statistical Method. Iowa State Univ. Press, Ames. 
Terdwongworakul A., S. Chaiyapong, B. Jari mopas, and W. Meeklangsaen. 2009. Physical properties of fresh young Thai coconut for maturity sorting. Biosys. Eng. 103: 208-216.

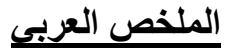 \\ خواص المرونة لثلاثة أصناف من ثمار التمر خلال ثلاث مراحل مختلفة للتضج

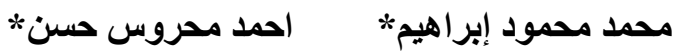

يهدف هذا البحث إلى تقدير الخو اص الطبيعية وخو اص المرونـة لثلاثثة أصـناف من ثمـار التمـر (تاليس - خضرى - تغيات) أثناء مر احل النضج (خلال، رطب، تمر ) المنزر عة في سبها ليبيا،

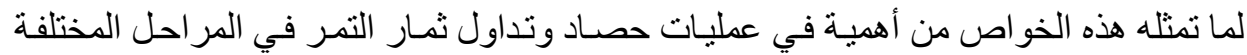

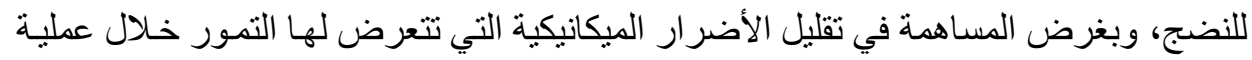
النقل و التخزين من خلال التتبؤ بارتفاع عبو ات قادرة على الحفاظ على الثمار من هذه الأضر ار. وقد تم تقدير كل من الخو اص البعديـة للثمرة، سمك اللحم، المحتوى الرطوبى للثمرة، الكثافة

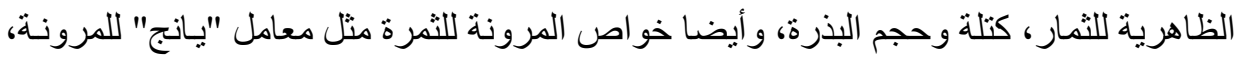

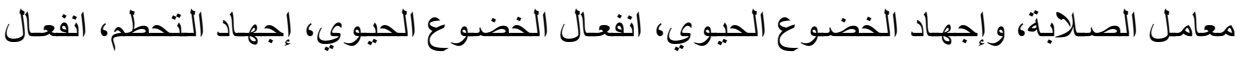

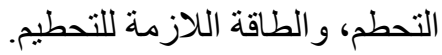

\section{و قد بينت الدراسة ما يليى:}

ا. توجد فروق معنوية بين مر احل نضح الثمرة في معظم الخصائص الطبيعية للثلاثة أصناف. ץ. توجد فروق معنويـة بين مر احل نضـح الثمرة في الخصـائص الميكانيكيـة للثناثة أصناف:

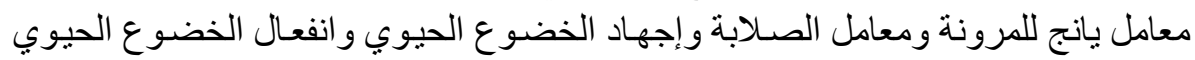

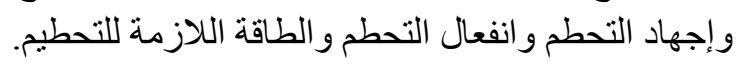

ب. وجد أن خو اص معامـل يـانج للمرونـة ومعامل الصـلابة و إجهاد الخضـوع الحيوي و إجهاد التحطم و الطاقة اللازمة للتحطيم تقل من مرحلة الخلال إلى مرحلة الرطب ثم ثمد بعد ذلك تزيد من مرحلة الرطب إلى مرحلة التمر وذلك مع أصناف التمر الثلاثة.

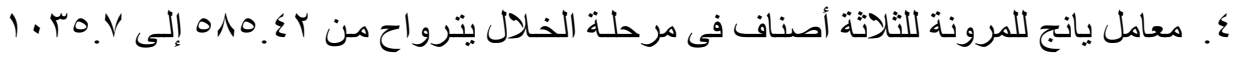

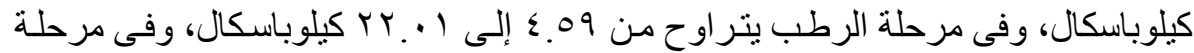

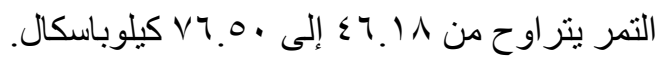

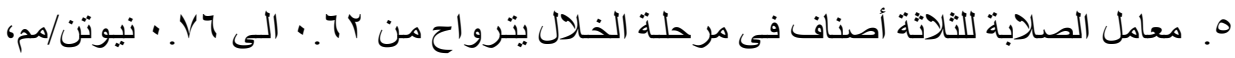

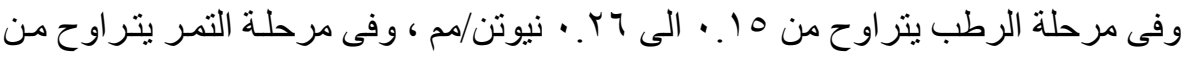

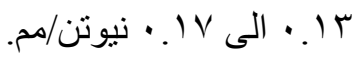

* مدرس الهندسة الزراعية ـ كلية الزراعة ـ جامعة القاهرة. 


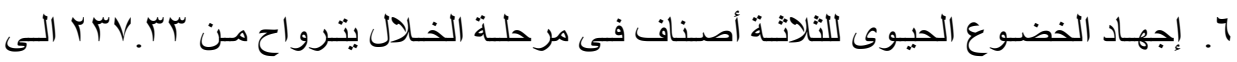

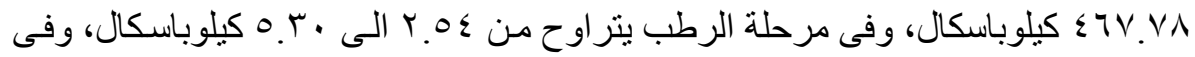

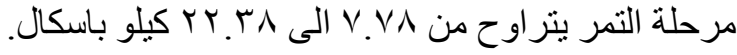

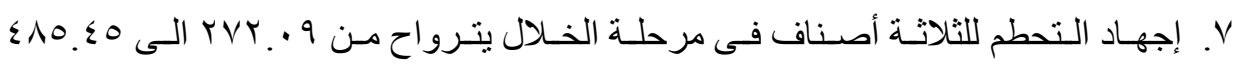

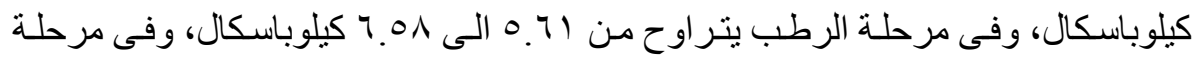

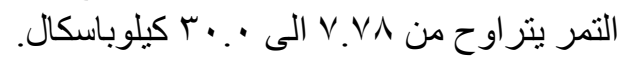

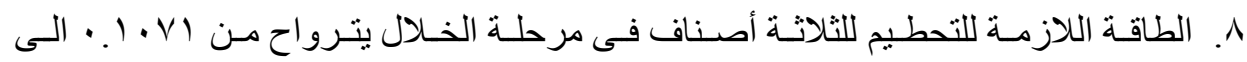

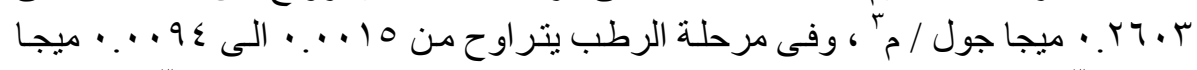

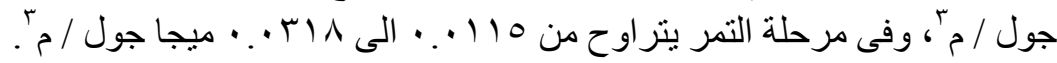

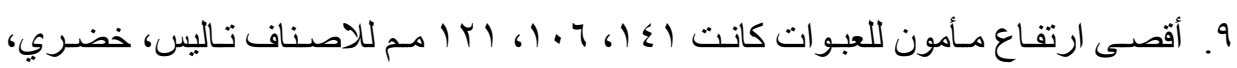
تغيات على الترتيب. 